\title{
A Central India Perspective on Leprosy and Its Association with Diabetes Mellitus
}

\author{
Amritava Ghosh ${ }^{1}$ \\ ${ }^{1}$ Department of Endocrinology and Metabolism, All India Institute \\ of Medical Sciences, Raipur, Chhattisgarh, India
}

J Soc Health Diab 2019;7:37-38

Although India has achieved significant reduction in prevalence of leprosy since the mid-1980s, pockets of high endemicity and ongoing transmission still persist., ${ }^{1,2}$ The central Indian state of Chhattisgarh, in particular, shows high leprosy rates with prevalence ( 2.52 per 10,000 population) and annual case detection rates (ANCDR) (43.69 per 100,000 population) approximately four times the national average. With a population of just $2.17 \%$ of India's population, Chhattisgarh accounts for $8.24 \%$ of case load and $9.31 \%$ of new cases. Highest ANCDRs are reported from the districts of Raigarh (108.15) and Mahasamund (91.83). Several other districts also report ANCDR of more than 50. Of particular concern is the high grade 2 disability rate of 5 to $15 \%$ among new cases reported from the state that indicates presence of hidden cases in community and delay in diagnosis. ${ }^{1}$ Thus the actual number of cases in the community is expected to be much higher. Also, a significant number of leprosy patients are managed by dermatologists who do not report to the government agencies and are thus not accounted for. ${ }^{2}$

Diabetes mellitus (DM) is a global health issue that also shows high prevalence among Indians. In areas with high leprosy prevalence, DM and leprosy are often found to coexist in the same patient. DM and leprosy can interact with each other in a number of ways, as follows:

- Patients with leprosy were found to have higher insulin resistance and greater prevalence of prediabetes and DM compared with controls. This may be attributable to a number of factors such as fever, malnutrition, inactivity, and proinflammatory cytokines (e.g., tumor necrosis factor- $\alpha[$ TNF- $\alpha$ ). Fatty acid transporter protein expressed by Mycobacterium also contributes to dysregulation of energy homeostasis and predisposition to DM. Thus, patients with leprosy should be screened for the presence of DM. Treatment of leprosy was shown to be associated with improvement in glycemic control., ${ }^{3,4}$

- Lepra reactions (types 1 and 2) are immunologically mediated inflammatory states that frequently affect
Address for correspondence Amritava Ghosh, MBBS, MD, DM, Department of Endocrinology and Metabolism, All India Institute of Medical Sciences, G.E. Road, Tatibandh, Raipur 492099, Chhattisgarh, India (e-mail: amritava_ghosh@yahoo.co.in).

patients with leprosy. Lepra reactions often require therapy with systemic glucocorticoids that can predispose to steroid-induced DM or worsen glycemic control in DM. ${ }^{5}$ Frequent monitoring of glucose levels is important in these patients.

- The cellular immune response to Mycobacterium leprae is impaired in DM. Additionally, leprosy-associated wounds are predisposed to bacterial infections. ${ }^{3}$ Thus coexistent DM complicates the management of leprosy.

- Both DM and leprosy are important causes of peripheral neuropathy and can lead to similar long-term sequelae such as neuropathic pain, chronic ulcers, Charcot's osteoarthropathy, and deformities. ${ }^{5-8}$ Peripheral neuropathy caused by leprosy may be misdiagnosed as a complication of DM. The resultant delay in diagnosis of leprosy may lead to development of severe deformities. ${ }^{6}$ Hence, it is important to consider the diagnosis of leprosy in a patient from leprosy endemic area presenting with neuropathy, even if DM is present. ${ }^{6,8}$ Early diagnosis and treatment of leprosy can prevent disabilities. ${ }^{3}$

- Muscle weakness and deformities associated with leprosy impair dexterity and may interfere with the patient's ability to perform DM self-care tasks, such as glucose monitoring and insulin administration. ${ }^{5}$

- Rifampicin used in therapy of leprosy shows important drug interactions with certain antihyperglycemic agents. Rifampicin interacts with some sulfonylureas (e.g., glibenclamide) and pioglitazone via the cytochrome P450 system and affects glycemic control. Blood glucose levels should be closely monitored and drug dose adjustment made in patients receiving these drugs. ${ }^{8}$

- Given the common morbidity sequelae of the two conditions, combined clinics providing integrated services for neuropathy-associated complications of the two conditions may improve outcomes in areas where leprosy is prevalent.7 Such clinics may promote detection of hidden cases of leprosy and reduction in stigma associated with leprosy.

\section{received}

February 20, 2019

accepted

March 5, 2019
DOI https://doi.org/

$10.1055 / \mathrm{s}-0039-1692334$

ISSN 2321-0656.
C2019 Novo Nordisk Education

Foundation
License terms

(1) (1) $\circledast$ 


\section{Conflict of Interest}

None declared.

\section{References}

1 National leprosy eradication programme. NLEP Annual Report 2016-2017. Available at: http://www.nlep.nic.in/pdf/Annual\%20report_\%202016-17.pdf. Accessed February 20, 2019

2 Rao PN, Suneetha S. Current situation of leprosy in India and its future implications. Indian Dermatol Online J 2018;9(2):83-89

3 Saraya MA, Al-Fadhli MA, Qasem JA. Diabetic status of patients with leprosy in Kuwait. J Infect Public Health 2012;5(5):360-365

4 Nigam P, Dayal SG, Srivastava P, et al. Diabetic status in leprosy. Hansenol Int 1979;4(1):7-14
5 Lockwood DNJ. Chronic aspects of leprosy-neglected but important. Trans R Soc Trop Med Hyg 2019;00:1-5

6 Rawson TM, Anjum V. Leprosy interpreted as diabetes related complications. Indian J Lepr 2014;86(2):65-67

7 van Crevel R, van de Vijver S, Moore DAJ. The global diabetes epidemic: what does it mean for infectious diseases in tropical countries? Lancet Diabetes Endocrinol 2017;5(6):457-468

8 Gardiner BJ, Machado PRL, Ooi WW. Comorbidities in patients with Hansen's disease. In: Scollard DM, Gillis TP, eds. The International Textbook of Leprosy. Available at:https://internationaltextbookofleprosy.org/chapter/co-morbidities-patientshansens-disease. Accessed February 19, 2019 